\title{
Origin Determination and Differentiation of Gelatin Species of Bovine, Porcine, and Piscine through Analytical Methods
}

\author{
Hatice Saadiye Eryılmaz*, Beyza Şükran Işık, Evren Demircan, Zahide Memeli, \\ Dilara Nilüfer Erdil, Esra Çapanoğlu
}

Department of Food Engineering, Faculty of Chemical and Metallurgical Engineering, Istanbul Technical University, 34469 Maslak/Istanbul, Turkey

\section{A R T I C LE IN F O}

\section{Review Article}

Received 16 November 2016

Accepted 08 May 2017

Keywords:

Gelatin

Authentication

Food safety

Food analysis

Computational databases

*Corresponding Author:

E-mail: saadiyyee@yahoo.com

\begin{abstract}
A B S T R A C T
Gelatin origin determination has been a crucial issue with respect to religion and health concerns. It is necessary to analyze the origin of gelatin with reliable methods to ensure not only consumer choices but also safety and legal requirements such as labeling. There are many analytical methods developed for detection and/or quantification of gelatin from different sources including bovine, porcine and piscine. These analytical methods can be divided into physicochemical, chromatographic, immunochemical, spectroscopic and molecular methods. Moreover, computational methods have been used in some cases consecutively to ensure sensitivity of the analytical methods. Every method has different advantages and limitations due to their own principles, applied food matrix and process conditions of material. The present review intends to give insight into novel analytical methods and perspectives that have been developed to differentiate porcine, bovine and piscine gelatins and to establish their authenticity. Almost every method can be succeeded in origin determination; however, it is a matter of sensitivity in that some researches fail to ensure sufficient differentiation.
\end{abstract}

DOI: https://doi.org/10.24925/turjaf.v5i5.507-517.1077

\section{Introduction}

Gelatin is a water soluble protein obtained by hydrolysis of collagen to several high molecular weight polypeptides. While the main component of the gelatin is protein $(85-92 \%)$, it also contains mineral salts and moisture (Baziwane and He, 2003; Schrieber and Gareis, 2007). Gelatin has a great importance in pharmaceutical, cosmetic and especially food industry with its well-known functional properties such as gel formation in jellies, foam formation and stabilization in ice cream, emulsion stabilization in meat products, syneresis stabilization in yogurt (Nhari et al., 2012). Gelatin was produced approximately 326.000 metric tons in 2008 worldwide, and it is estimated to be consumed 395.840 metric tons by the year of 2017 according to Global Industry Analysts, Inc. which is one of the largest and reputed market research companies (Anonymous, 2016). The raw materials used in gelatin production are mainly from bovine and porcine sources: $80 \%$ from pig skin, $15 \%$ from cattle hide split, the remaining $5 \%$ from bones, fish and other sources (GME, 2016). Gelatin origin determination has been a matter of paramount importance for Muslims, Hindus, Jews, vegetarians and vegans, in that, in Islam and Judaism, porcine derivatives are prohibited to consume, whereas in Hinduism, cow can neither be slaughtered nor consumed. Vegetarians and vegans prefer to eat animal-free foods (Boran et al., 2010; Nhari et al., 2012). Moreover, bovine gelatin has been restricted for human consumption due to Bovine Spongiform Encephalopathy (BSE) outbreak in 1986 in England and other countries (Venien and Levieux, 2005). Therefore, it is necessary to analyze the origin of gelatin with a reliable method. As far as it is concerned; physiochemical, chromatographic, immunochemical, spectroscopic and molecular methods have been developed to determine and differentiate gelatin origin (Doi et al., 2009; Nhari et al., 2012). Every method has its own principles, advantages, and drawbacks. The analytical method studies examining identification and differentiation of gelatin origin (porcine and bovine) up to 2010, have been indicated in the review article written by Nhari et al. (2012). However, new methods and different perspectives to differentiate origin of the gelatins are established in recent years. For example, computational methods and combinations of databases have been involved in studies concerning differentiation of gelatin species. Moreover, there is a growing interest for piscine gelatin because it is a good alternative to bovine and porcine gelatins due to its abundance, biodegradability, 
film-forming property, appropriate barrier capacity against oxygen and aromas, and affordable price (Benbettaïeb et al., 2016; Gómez-Guillén et al., 2002). By using optimized extraction conditions, it is even possible to obtain better gelling ability than those of the mammalian ones with warm water piscine gelatins as in the case of Yellowfin Tuna fish (Cho et al., 2005). Therefore, it has been aimed herein to give brief information about the analytical methods concerning the identification and differentiation of bovine, porcine and piscine gelatins in recent studies via summarizing principles, advantages and disadvantages of each method.

\section{Analytical Methods}

\section{PCR Based Techniques}

Polymerase chain reaction (PCR) is a technique among the molecular analytical methods, which provides millions of copy of a few fragment of DNA in very short periods of time (Saiki et al., 1985). PCR amplification is based on DNA replication in in vitro conditions by using specific oligonucleotides as primers to target DNA and synthesize millions of copies (Nakyinsige et al., 2012). A PCR cycle consists of three steps which are denaturation, annealing and extension. Denaturation step requires high temperature around $93-96^{\circ} \mathrm{C}$ and allows the separation of the double stranded DNA helix. Lower temperatures (generally between $55-65^{\circ} \mathrm{C}$ ) are required for annealing step of cycle in which primers bind to the appropriate parts of single stranded DNA. After that, heat stable DNA polymerase enzyme (generally Taq polymerase) binds to this primer template structure and starts to copy the main chain. In the last step of a cycle, the primers are extended across the target sequence by using a heat stable DNA polymerase. To create a pair of the targeting material, nucleotide triphosphates containing deoxyribose (dNTPs) are used. This step usually performed at $72^{\circ} \mathrm{C}$ which is the optimum working temperature of Taq polymerase enzyme (Somma and Querci, 2006). After applying many cycles repeatedly, a large number of targeted genes can be produced.

Due to the low amounts of DNA amplifying capability and high detection limit of PCR technique, it is served as an alternative to identification and quantification of meat and meat products originated from different species. Developing or selecting appropriate primer is essential for a successful determination of species of sample (Sentandreu and Sentandreu, 2011). Besides choosing proper and sufficient genetic material, it is another important issue to develop a susceptible assay. Although, mitochondrial DNA and nucleus DNA can be used as a targeting gene, mitochondrial DNA is mostly used due to its advantages such as availability in extracted DNA (Murugaiah et al., 2009). Mitochondrial DNA also evolves faster compared to nucleus DNA. Cytocrome b (cyt b), ATP 6 and 12S rRNA are mostly used mitochondrial genes as markers to develop PCR assays for meat species authentication (Abd Mutalib et al., 2015; Chen et al., 2010a; Murugaiah et al., 2009). There are various types of PCR analysis which have been used for determination of species of meat and meat products, and gelatin, as well.

\section{The Conventional PCR}

Conventional PCR technique is based on amplification of DNA fragments. After the PCR amplification, the produced DNA is investigated with agarose gel electrophoresis with respect to their fragment sizes in order to determine the presence of any species (Nakyinsige et al., 2012). Restriction fragment length polymorphism analysis (PCR- RFLP) is one of the commonly used methods to determine the species adulteration of meat (Aida et al., 2007; Murugaiah et al., 2009). Although this technique is known for its low cost, simplicity and adoptability to routine analysis, it is not applicable in processed foods like gelatin due to DNA degradation (Fajardo et al., 2010).

\section{Species Specific PCR}

Another PCR technique which is commonly used is species specific PCR. In this technique, a targeted DNA sequence can be amplified precisely. Shabani et al. (2015) have developed a new method based on species specific PCR technique to investigate halal authenticity of gelatin. Mitochondrial cyt b gene was targeted and two sets of specific bovine and porcine primers were used.

\section{5'-GCCATATACTCTCCTTGGTGACA-3', 5'-GTAGGCTTGGGAATAGTACGA-3' and \\ 5'-GCCTAAATCTCCCCTCAATGGTA-3, \\ 5'-ATGAAAGAGGCAAATAGATTTTCG-3'}

for bovine and porcine, respectively.

Binary gelatin mixtures prepared with different concentrations by using standard bovine and porcine gelatins. Additionally, eight commercial gelatin containing food products and eight commercial gelatin capsules were investigated with both methods. After gel electrophoresis of amplified samples it is found that the developed method was very sensitive (as low as $0.1 \%$ ), specific and affordable for routine analyses of adulteration on gelatin containing foods and capsules (Shabani et al., 2015). Furthermore, multiplex PCR assays can be used with species-specific primers to multiple target detection at the same time. This technique provides reduction in time and cost of assays (Ali et al., 2015). However, there is no study about gelatin differentiating methods conducted with multiplex PCR assays.

\section{Real-Time PCR (Quantitative PCR / qPCR)}

Real-time PCR (quantitative PCR / qPCR) is another method to detect the species of meat products. The differences of this method from the other PCR methods are directly monitoring of amplification products by using different chemistries such as fluorescent dyes and sequence-specific DNA probes. Real-time PCR assays have been increasingly used for specific, sensitive and quantitatively detection of species specific DNA fragments in meat products. Due to its specificity and low detection limits, it is preferred to determine species of processed products (Cai et al., 2012; Hanna et al., 2005). 
Cai et al. (2012) represented two species-specific realtime PCR assay as simple, reliable and sensitive method for detection and quantification of bovine and porcine DNA in gelatin mixtures and capsules. They have used two species-specific (bovine and porcine) quantitative PCR assays based on repetitive elements. Different concentrations of porcine and bovine standard mixtures were prepared and the closeness of measurements and theoretical values were observed. High specificity and lack of cross-reactivity with any other species of DNA were reported against the developed qPCR assays. Additionally, qPCR assays allowed sensitive detection and quantification of bovine and porcine species as low as $1 \mathrm{pg} / \mathrm{mL}$ The fact that significantly fewer amounts of DNA were detected in gelatin capsules maybe due to extra processes applied in capsule production of gelatin (Cai et al., 2012). In another study, a simple method is developed for routine analyses in food control laboratories to determine whether the gelatins are adulterated or mislabeled (Demirhan et al., 2012). Researchers used commercial real-time PCR and test kits to extract DNA from food materials. Forty-three gelatin containing food were collected from Turkey and Germany consisting of gum drops, jellies, marshmallows, cakes and Turkish delight. $1 \%$ contamination level was assumed as a pragmatic level for a practical usage. The results indicated that, porcine gelatin was detected in two of eleven different food products from Germany and one of thirty-two different food products from Turkey which are unlabeled. However, a false negative data, which is the amount of porcine detected to be zero although the samples include porcine, was obtained in a $5 \%$ porcine gelatin containing control sample. It is indicated that the applied method was not very sufficient and robust. Finally, the results showed that using real-time PCR with commercial DNA extraction kit provides detection of porcine DNA in food products as low as $1 \%$, like in Cai et al. (2012), with a 2\% false negative rate (Cai et al., 2012; Demirhan et al., 2012).

\section{PCR Combined with Southern Hybridization}

Abd Mutalib et al. (2015) reported a technique which is a combination of PCR and southern hybridization in order to be used in analysis of halal authentication of gelatin capsules. The researchers also compared their results with conventional PCR. In the combined technique, by using a commercial porcine gene chip and a set of primer targeting mitochondrial DNA cyt b (biotin labeled oligonucleotide primer); the PCR-southern hybridization on chip assay was developed. Twenty different brand gelatin capsules were investigated with both methods and porcine DNA was detected in six of them by PCR-southern hybridization on chip assay, whereas no porcine positive detection was observed by conventional PCR. Limit of detection of porcine DNA was determined as $0.001 \mathrm{ng}$. PCR-southern hybridization on chip assay was reported as applicable for highly processed foods, such as gelatin, relying on its ability to detect very low concentration of porcine DNA (Abd Mutalib et al., 2015).
When overall studies on PCR based methods for detection of different species of gelatin were reviewed, it has been observed that there are some advantages and disadvantages of different types. PCR based techniques are widely used to detect species origin in many meat products; however, there are limited studies intended for gelatin differentiation (Abd Mutalib et al., 2015; Cai et al., 2012; Demirhan et al., 2012; Grundy et al., 2016; Shabani et al., 2015). These techniques provide results through DNA sequence level, so it has high specificity, sensitivity, and discriminating power (Nakyinsige et al., 2012). Protein based techniques have some limitations in processed meat products due to denaturation of proteins during thermal processes. Moreover, DNA is more stable with temperature changes in analysis of processed foods and highly specific to species (Nakyinsige et al., 2012). These are general advantages of PCR based techniques. However, gelatin is a highly processed meat product and leaves very few amount of DNA after processes and lower chain length fragments due to DNA damage. These DNA fragments with lower chain length exhibit the specificity of PCR assays (Sentandreu and Sentandreu, 2011). It is possible to obtain lower detection limits and detection values consistent with theoretical ones by direct testing of gelatin (Abd Mutalib et al., 2015; Cai et al., 2012; Demirhan et al., 2012; Grundy et al., 2016; Shabani et al., 2015). On the other hand, gelatin is added in very low concentrations to the food products as an ingredient, in addition; DNA level further decreased by extra processing and DNA damage increased. Hence, detection of gelatin species became difficult.

\section{Fourier Transmission Infrared Spectroscopy (FTIR)}

Fourier transmission infrared spectroscopy (FTIR) is a non-destructive and practical method among the spectroscopic analytical methods giving information about molecular structure and composition (Sivakesava and Irudayaraj, 2002). FTIR is an effective way to measure adulteration in food industry. It can be combined with attenuated total reflectance (ATR). ATR element and sample are in contact, which enables to obtain the spectrum. ATR technique provides minimizing the sample amount and radiation through the sample without transmission (Griffiths and De Haseth, 2007). A typical gelatin spectrum can have low intensified Amide A (3600-2300 $\left.\mathrm{cm}^{-1}\right)$, Amide I (1656-1644 $\left.\mathrm{cm}^{-1}\right)$, Amide II (1560-1335 $\left.\mathrm{cm}^{-1}\right)$, and much lower Amide III (1240-670 $\mathrm{cm}^{-1}$ ) bands. Low intensity of Amide III band can be explained by denaturation of collagen to gelatin and loss of triple helix state during extraction of gelatin (Muyonga et al., 2004). The most differentiations between bovine and porcine gelatins were found in $3290-3280 \mathrm{~cm}^{-1}$ and $1660-1200 \mathrm{~cm}^{-1}$ (Hashim et al., 2010). The obtained spectrums of bovine and porcine gelatins can be found very similar using 4000-650 $\mathrm{cm}^{-1}$ resolution. Cebi et al. (2016) studied to differentiate porcine, bovine and fish gelatins by ATR-FTIR. They found that even though all kind of gelatin spectrums are similar, fish gelatin can be separated from bovine and porcine gelatin in 1100-1000 $\mathrm{cm}^{-1}$ spectral range. While the concentrations of gelatin 
content in the solutions increase, the intensities of Amide I and II bands improve (Cebi et al., 2016). To classify bovine and porcine gelatins, Amide III band becomes important. $1313-11124 \mathrm{~cm}^{-1}$ spectral range provides to separate bovine and porcine gelatins from each other. The results indicate that classification of bovine, porcine and piscine gelatins are achieved with $100 \%$ accuracy (Cebi et al., 2016).

\section{Electrophoretic Methods}

\section{Polyacrylamide Gel Electrophoresis (PAGE)}

Polyacrylamide gel electrophoresis (PAGE) is an applicable method among the physiochemical methods for species determination. PAGE is preferred because it is easy, simple, and fast. It has been used in milk, cheese (Mayer, 2005), raw (Chen et al., 2010b) and cooked fish (Etienne et al., 2000). Azira et al. (2014) have studied with sodium dodecyl sulphate polyacrylamide gel electrophoresis (SDS-PAGE) for determination of bovine and porcine gelatin species with respect to their molecular weight. In the literature, the molecular weights of porcine gelatin polypeptides are ranged from 53 to $220 \mathrm{kDa}$ and they are more heterogeneous than those of bovine gelatin (Schrieber and Gareis, 2007). Azira et al. (2014) also found that porcine gelatin has 16 bands and their molecular weights are ranged from 58 to $160 \mathrm{kDa}$. On the other hand, bovine gelatin has 2 dominant bands and their molecular weights are 135 and $110 \mathrm{kDa}$. By looking at the results, bovine and porcine gelatin cannot be separated by number of bands, however; differentiation can be obtained by the help of different intensities of the bands. Porcine gelatin in bovine gelatin can be identified at $5 \%$ by SDS-PAGE method but adulteration of porcine gelatin with bovine gelatin cannot be detected by SDS-PAGE. Nevertheless, this method does not require an expensive equipment, high sample purity and time consuming sample preparation. Moreover, the results were not affected by DNA degradation caused by gelatin manufacturing process (Azira et al., 2014).

\section{Two-Dimensional Electrophoresis (2-DE)}

Two-dimensional electrophoresis (2-DE) is a promising and powerful separation technique among the physical-chemical methods for resolution of several proteins (Beranova-Giorgianni, 2003; Cellulaire, 2002). Determination of gelatin origins by 2-DE can be obtained with respect to molecular weight and isoelectric point. Aina et al. (2013) studied about determination of gelatin origin by 2 -DE method. They emphasized that the preparation steps are very important to get high resolution of protein separation in 2-DE gel. Salts, minerals and other interfering compounds can affect the results so the method has to be applied thoroughly (Isola et al., 2011; Schrieber and Gareis, 2007). High resolution of protein separation can be obtained by applying protein precipitation with cold acetone. Bovine gelatin was adulterated with porcine gelatin in a proportion ranging from 1 to $5 \%(\mathrm{v} / \mathrm{v})$. According to their findings, 2-DE method is an easy and trustable method even if the percentage of porcine gelatin in the solution is $1 \%$. However, sample preparation and inconsistent exposure time during experiment can influence the results negatively (Nishihara and Champion, 2002).

\section{Enzyme Linked Immune Sorbent Assay (ELISA) Method}

Detection and quantitation of gelatin in food and pharmaceutical products have also been achieved by immunochemical methods which are less expensive, can be completed in shorter time and do not require highly skilled staff (Tukiran et al., 2016a; Venien and Levieux, 2005). ELISA is among the types of immunochemical analytical methods. Not only the type and quality of gelatin but also the used concentration of gelatin affects the results with these methods, in that low quality or concentrations of a sample can either lead to false positive or false negative results. Moreover, these methods are not suggested for commercial gelatins. Competitive indirect ELISA has allowed detecting porcine acidic gelatins with around 10-fold higher sensitivity than their bovine counterparts. However, the porcine limed bone has not been detected by competitive indirect ELISA (Venien and Levieux, 2005). Tukiran et al. (2016a) investigated limit of detection of $0.05 \mathrm{mg} / \mathrm{mL}$ which is satisfactory for the scope of adulteration lower than this would not be economically profitable and prone to cross contamination problem. Weber et al. (2009) developed a competitive indirect ELISA which was applied to several fish gelatins and isinglass samples used in food production for the determination of parvalbumins from various fish species. Competitive indirect ELISA detected parvalbumins within a range of $0.1-0.5 \mathrm{mg} / \mathrm{L}$. Antibody binding was strongly inhibited between 0.1 and $100 \mathrm{mg} / \mathrm{L}$ (Weber et al., 2009). Tukiran et al. (2016b) also developed a competitive indirect ELISA to determine gelatin sources in commercial confectionery products. To select the protein that used they analyzed porcine gelatin by SDSPAGE. Jellies with defined amounts of porcine gelatin showed the recovery rates in a range between 90.28 and $114.51 \%$. Specificity, accuracy, sensitivity and repeatability suggested that the developed ELISA is suitable for determination of mammal gelatin in commercial processed products such as jelly, gummy, marshmallow and premix powder (Tukiran et al., 2016b).

High Performance Liquid Chromatography with Mass Spectroscopy or Chemometrics

High performance liquid chromatography (HPLC) techniques have been widely used as a chromatographic analytical method to detect the origin of gelatin species. Gelatins of different origin are first digested with trypsin. Then, specific sequences of peptides are formed, which are further identified with a type of mass spectrometry (MS) or a chemometric technique (Zhang et al., 2009; Zhang et al., 2006). Many HPLC techniques have been investigated by researchers in recent years to reach a cost and time-efficient and highly sensitive and accurate method of differentiation. Due to the fact that the species desired to be differentiated has been generally of bovine and porcine gelatin, which have same chemical and 
electrophoretic properties and are affected similarly from harsh process conditions, chromatographic methods alone has failed to differentiate them (Azilawati et al., 2015; Nemati et al., 2004). There are a great number of methods from laboratory based to computational ones used in combination with chromatographic methods in order to achieve the purpose of differentiation; their comparison can be followed at Table 1 .

Table 1 Differentiation of gelatin species using chromatographic methods coupled with mass spectroscopic or chemometric methods

\begin{tabular}{|c|c|c|c|}
\hline Method name & Advantages of the method & Limitations of the method & Reference \\
\hline $\begin{array}{l}\text { UPLC/Q-TOF-MS } \\
\text { coupled with PCA }\end{array}$ & $\begin{array}{l}\text { A faster UPLC/Q-TOF-MS tryptic peptides } \\
\text { profiling assay with better chromatographic peak. } \\
\text { Reduced severe ion suppression. } \\
\text { PCA serves sensitive profiling at low } \\
\text { concentrations. } \\
\text { Good for gelatin mixtures. }\end{array}$ & $\begin{array}{l}\text { Not for all marker } \\
\text { peptides. } \\
\text { Non-collagen based } \\
\text { markers cannot be } \\
\text { identified. } \\
\text { Still complex due to } \\
\text { gelatin homology. } \\
\text { Long time for profiling. }\end{array}$ & $\begin{array}{l}\text { Cheng et al. } \\
(2012)\end{array}$ \\
\hline $\begin{array}{l}\text { Nano UPLC/ESI- } \\
\text { TOF-MS }^{\mathrm{E}}\end{array}$ & $\begin{array}{l}\text { High protein identification score. Enabled complex } \\
\text { mixture analysis. } \\
\text { High sensitivity at lower concentrations than the } \\
\text { previous high resolution mass spectrometry } \\
\text { systems. } \\
\text { Combination of nanoUPLC and SYNAPT HDMS } \\
\text { is advantageous. } \\
\text { Even shape of molecules can be identified. }\end{array}$ & $\begin{array}{l}\text { Careful pursuit and } \\
\text { comprehensive work and } \\
\text { time. } \\
\text { Further studies required } \\
\text { to utilize } \mathrm{MS}^{\mathrm{E}} \text { for } \\
\text { quantification. } \\
\text { Very expensive } \\
\text { instrument. } \\
\text { Highly skilled personnel. }\end{array}$ & $\begin{array}{l}\text { Yilmaz et } \\
\text { al. (2013) }\end{array}$ \\
\hline MALDI-TOF-MS & $\begin{array}{l}\text { Specific trypsin digested peptide peaks for porcine } \\
\text { and bovine obtained. } \\
\text { Potential for the systematic and routine traceability } \\
\text { of collagen. } \\
\text { No qualified personnel and high-performance } \\
\text { instruments requirement. }\end{array}$ & $\begin{array}{l}\text { Low sensitivity and } \\
\text { unsuitable for } \\
\text { traceability. }\end{array}$ & $\begin{array}{l}\text { Flaudrops et } \\
\text { al. (2015) }\end{array}$ \\
\hline $\begin{array}{l}\text { PEME coupled with } \\
\text { HPLC-UV }\end{array}$ & $\begin{array}{l}\text { A practical, simple and efficient technique using } \\
\text { two specific amino acid peaks of porcine gelatin } \\
\text { (Asn and Gln). } \\
\text { Easier follow up the traceability of porcine gelatin. }\end{array}$ & $\begin{array}{l}\text { Pre-treatment steps can } \\
\text { require comprehensive } \\
\text { work and time. } \\
\text { Not applicable for } \\
\text { quantification of gelatin } \\
\text { mixtures. }\end{array}$ & $\begin{array}{l}\text { Rezazadeh } \\
\text { et al. (2015) }\end{array}$ \\
\hline $\begin{array}{l}\text { RP-HPLC with AQC } \\
\text { reagent and } \\
\text { normalized PCA }\end{array}$ & $\begin{array}{l}\text { Successful differentiation of the bovine, porcine } \\
\text { and fish gelatin into three distinct groups. } \\
\text { Better derivation of amines in a shorter time and } \\
\text { more analytical way with reagent choice of AQC. }\end{array}$ & $\begin{array}{l}\text { Required area } \\
\text { normalization and mean } \\
\text { centering adjustments. } \\
\text { Separated not all but } 16 \\
\text { of } 20 \text { amino acids. } \\
\text { Resolution problems, } \\
\text { high temperature and } \\
\text { extensive period of time } \\
\text { for process. }\end{array}$ & $\begin{array}{l}\text { Azilawati et } \\
\text { al. (2015) }\end{array}$ \\
\hline $\begin{array}{l}\text { MALDI-TOF-MS } \\
\text { and (ESI)-LC- } \\
\text { MS/MS coupled } \\
\text { with a collagen } \\
\text { database }\end{array}$ & $\begin{array}{l}\text { Capable of determining the number of } \\
\text { hydroxylated proline within peptides; indicators of } \\
\text { marker peptide degradation. } \\
\text { More robust technique than before, able to detect } \\
\text { some of the published 'bovine-determinant' while } \\
\text { testing porcine gelatin and vice versa. Analyzed a } \\
\text { wide range of samples. Combined experimental and } \\
\text { published data, and computational programs. }\end{array}$ & $\begin{array}{l}\text { Future quantitative } \\
\text { analysis would be useful } \\
\text { to confirm the } \\
\text { composition of the } \\
\text { mixtures. }\end{array}$ & $\begin{array}{l}\text { Grundy et } \\
\text { al. (2016) }\end{array}$ \\
\hline
\end{tabular}




\section{UPLC/Q-TOF-MS Method Coupled With PCA}

Collagen marker peptides followed by sequence searching can be used to differentiate origins of gelatin species by utilizing time of flight mass spectrometry (TOF) since it is useful for protein analysis (Nimptsch et al., 2011). Cheng et al. (2012), referring to previous applications of the technique, have used collagen marker peptides to differentiate bovine, porcine, donkey (hide) gelatins and tortoise shell glue, and deer-horn glue (Nemati et al., 2004; Zhang et al., 2006). They have coupled the method with PCA analysis to have uniqueness. Via combination of TOF/MS detection and using of a sub-2 micrometers particle column, a significantly faster (55 min) UPLC/QTOF-MS tryptic peptides profiling assay with better chromatographic peak resolution than that of previous study was obtained. By this method, one of the problems of chromatographic separation, which is severe ion suppression, was expected to be reduced, whereas the other source of the problem, the complexity of the tryptic gelatin peptides, still exists due to homology of collagen in Total Ion Chromatography (TIC). That is why, further sample profiling of the gelatins included multivariate statistical tools, in that, the 3D LC/MS dataset was converted into a 2D matrix. Positive ion base peak intensity chromatograms used for marker peptides gave results as follows: (A) donkey-hide gelatin, m/z 765.8556, doublycharged ion of fragment GEAGPAGPAGPIGPVGAR. (B) bovine-hide gelatin, m/z 641.3065, doubly-charged ion of fragment GEAGPSGPGPTGAR. (C) pig-hide gelatin, m/z 925.4326, doubly-charged ion of fragment GEPGPTGVQGPPGPAGEEGK. (D) tortoise shell glue $\mathrm{m} / \mathrm{z} 758.3530$ (E) deer-horn glue $\mathrm{m} / \mathrm{z}$ 732.8282. Since tortoise shell glue and deer-horn glue do not have collagen sequences, it was not possible to differentiate them by using sequences. However, the base marker peptides can still be an efficient way to differentiate them. The UPLC/Q-TOF-MS detection coupled with PCA allowed for details of the samples to be profiled so that not all but important markers of differences can be measured, even at low concentration levels, hence; can be used effectively for gelatin mixtures.

\section{Nano UPLC/ESI-TOF-MS Method}

Electrospray ionization quadrupole time-of-fligh mass spectrometry (ESI-qTOF-MS ${ }^{\mathrm{E}}$ ) is a proteomic method based on data independent acquisition mode, in which not precursor but a non-overlapping $\mathrm{m} / \mathrm{z}$ window was selected and all the precursor ions within the window were cofragmented (Yilmaz et al., 2013). It is known to yield more fragment ions per peptide and more peptides per protein, in turn, increase the protein identification score. Additionally, it enables the complex mixture analysis by providing masses of the precursor and fragment ions in parallel (Purvine et al., 2003). Yilmaz et al. (2013) have introduced this complex method to differentiate gelatins of different origin; bovine and porcine, including mixtures. Both ion mobility of UPLC and mode of the SYNAPT HDMS (high definition mass spectrometer with nano lock spray ion source) ensure enormously high sensitivity at lower concentrations than the previous high resolution mass spectrometry systems. Furthermore, this method is advantageous over traditional molecular methods such as NMR, electron microscopy, and X-ray crystallography, in that, it can determine even the shape of molecules. Label-free nanoUPLC-ESI-qTOF-MS system; a combination of nanoUPLC and SYNAPT HDMS was utilized in this study to differentiate gelatin mixtures in dairy food systems such as yoghurt, cheese, and ice cream. Although the method is novel and advantageous, the pre-treatments and experimental steps require careful pursuit, comprehensive work and time. Specific extraction after extracting all other proteins, overnight peptide trypsinization, and manual verification of proline hydroxylated peptide sequence can be stated among the pre-treatments. The MS/MS spectra of various peptides identified in porcine and bovine gelatins can be stated as follows: (A) MS/MS spectrum of a unique porcine peptide with the sequence GETGPAGPAGPVGPVGAR. (B) MS/MS spectrum of a modified porcine peptide with two proline hydroxylation. (C) MS/MS spectrum of a uniquely identified bovine gelatin peptide having IGQPGAVGPAGIR sequence. Gelatin mixtures, which were prepared in 90:10, 50:50 and 10:90 bovine to porcine standard sample ratios, were successfully identified with Nano liquid chromatography. On the other hand, since most intense peptides were identical between bovine and porcine gelatin peptides, $\mathrm{MS}^{\mathrm{E}}$ was not useful for quantification of gelatin mixtures; therefore, it was pointed out that filtration of species specific gelatin peptides and/or analyzing unique marker peptides can maintain this purpose in future studies.

\section{MALDI-TOF-MS Method}

As in the case of HPLC-MS and UPLC-QTOF-MS, tryptic peptides of gelatins can be analyzed by using reflectron Matrix-assisted laser desorption ionization time-of-flight mass spectrometry (MALDI-TOF-MS) system, again in a positive ion mode. Flaudrops et al. (2015) studied on determination of the origin of gelatin (porcine or bovine) in food preparations, such as candies; and herbal formulations, such as drugs; by using MALDITOF-MS. Tryptic peptide data of isotopic resolution mass spectra monitored between 700 and $4000 \mathrm{Da}$, manually compared for specific peaks to distinguish the gelatin source without ambiguity. Ten specific peaks were identified for porcine: $[\mathrm{M}+\mathrm{H}]^{+} 1177 \mathrm{Da}, 1180 \mathrm{Da}, 1666$ Da, 1892 Da, 2005 Da, 2188 Da, 2980 Da, 3265 Da, 3281 $\mathrm{Da}$ and $3605 \mathrm{Da}$. Thirteen were identified for bovine: $[\mathrm{M}+\mathrm{H}]^{+} 1192 \mathrm{Da}, 1297 \mathrm{Da}, 1308 \mathrm{Da}, 1427 \mathrm{Da}, 1580 \mathrm{Da}$, 1632 Da, 1769 Da, 1922 Da, 1975 Da, 2216 Da, 2404 Da, $2549 \mathrm{Da}$ and $2853 \mathrm{Da}$. Candies containing gelatin were crocodile candies (containing porcine gelatin), strawberry candies, marshmallows, and teddy bear candies. Candies without gelatin were cream desserts and halal candies (containing starch). Herbal formulations were collected from common brand drugs that claim to contain bovine gelatin such as capsules, coated tablets, two-piece hard capsules, and single-piece soft gel capsules. All candies and herbal formulations presented a common digested 
gelatin profile precisely specific for their labeled gelatin, either porcine or bovine. The means no adulteration established by looking at these profiles. The mixture of varying quantities of standard porcine gelatin and halal candies was analyzed to evaluate the sensitivity; the detection of less than $1 \%$ of gelatin in candies was performed without ambiguity concerning its origin. Moreover, the detection limit of porcine gelatin in bovine gelatin was found to be $20 \%$, below which the bovine gelatin signal was presumed to hide the porcine gelatin. Hence, this MALDI-TOF-MS technique has potential for the systematic and routine traceability of collagen, even at low concentrations; although it was noted for low sensitivity and unsuitable for traceability, it did not require highly qualified personnel and high-performance instruments as employed in molecular methods such as NMR (Flaudrops et al., 2015).

\section{PEME) Followed by HPLC-UV Method}

The amino acid compositions of porcine and bovine gelatins are different; asparagine (Asn) and glutamine (Gln) amino acids are present in porcine gelatin, whereas they are absent in bovine gelatin (Zhang et al., 2009); therefore origin determination can be maintained by amino acid analysis. Rezazadeh et al. (2015) introduced a pulsed electro membrane extraction method of amino acids coupled with high performance liquid chromatography-ultraviolet detector to differentiate bovine and porcine gelatins. Asn and Gln samples were derivatized with o-Phtalaldehyde (OPA) reagent to have UV absorbance and hydrophobicity/ lipophilicity prior to analysis; in addition, pulsed voltages were applied to make the analytes migrate through organic liquid membrane into an aqueous acceptor phase via hollow fiber-based liquid phase micro extraction method. In that way, pre-concentration of analytes was obtained enabling analysis in complicated matrices. The Asn and Gln amino acids were obtained in samples within their detection limits, and their existence in porcine gelatin was confirmed by HPLC-UV. This method was simple and efficient compared to previous electro membrane extraction methods (Rezazadeh et al., 2012); by looking at the chromatogram consisting of only two amino acid peaks, which are Asn and Gln, porcine and bovine origin can be determined, data further quantified with calibration curves. Differentiation analysis of gelatin mixtures was not performed in this study; however, it is possible to deduce that the trace of Asn and Gln marker peaks represented the existence of porcine gelatin; and further more sensitive differentiation studies may arise in future.

\section{RP-HPLC Using AQC Reagent Coupled with nPCA}

PCA is a chemometric technique that can be used as a screening method in correlation with fluorescence detector RP-HPLC method to reduce the dimensions of an interrelated data set of gelatins transforming it to uncorrelated principal components. Moreover, it has been reported to be difficult to define the relationship between samples and variables of spectral chromatographic multivariate data, in PCA. By the help of mean centering adjustment and area normalization pre-treatments to data of control gelatin samples, pattern recognition of different origins can be obtained. Azilawati et al. (2015) have performed differentiation of gelatins from bovine, porcine, and fish skin based on amino acid profiling via a RP-HPLC method with fluorescence detector that coupled with normalized PCA. This method was first introduced by Nemati et al. (2004) with less practical reagents and without normalization step. A 6-aminoquinolyl-Nhydroxysuccinimidyl carbamate (AQC) reagent was used in this study to separate the primary and secondary amines completely by derivatizing them to highly fluorescent urea in a same optimum excitation wavelength and shorter time than the derivation agents used in previous studies such as o-phthalaldehyde (OPA), 3mercaptopropionic acid (MPA) and 4-chloro-7nitrobenzofurazane (NBD-Cl) (Nemati et al., 2004). In a previous study of same researchers, pre-column derivation procedure with AQC reagent, which ensures good chromatographic separation for 18 amino acids, has been validated for amino acids composition in gelatinbased ingredients (Azilawati et al., 2014). However, there are 16 amino acids available in this study due to destruction of some amino acids under process conditions such as high temperature (Masuda and Dohmae, 2011). The 20 control gelatin samples of each known origin (porcine, bovine, and fish skin) were obtained from suppliers, and 12 gelatins of commercial brands ( 7 bovine and 5 porcine gelatins) were analyzed with respect to corresponding controls. Among the 16 amino acids; which are Hyp, Asp, Ser, Glu, Gly, Arg, Thr, Ala, Pro, Tyr, Val, Met, Lys, Ile, Leu and Phe; the Thr, Ser and Met contributing to the huge variances in the data correlated to fish gelatin; the non-polar side chains Pro, Hyp, Leu, Ile and Val positioning on the negative side of the PC1 found to be correlated to bovine gelatin, and polar side chain amino acids Asp, Glu, Lys and Tyr which form linear combination of variables correlated to porcine gelatin. As a result, successful differentiation of the bovine, porcine and fish gelatin into three distinct groups was obtained with the highest variance demonstrated by PC1 at $72 \%$. These results indicate that this method is able to differentiate gelatin mixtures in a simpler way than the previous studies with PCA (Azilawati et al., 2015).

MALDI-TOF-MS and (ESI)-LC-MS/MS: A Tryptic Peptide Mass Fingerprinting Method Coupled With a Collagen Database

Computational programs allowed researchers to generate new collagen databases by collecting and comparing data from high number of previous studies. Grundy et al. (2016), performed a comprehensive and complicated study on origin determination of gelatin species found in the food industry and their differentiation by using PCR, ELISA, and mass spectrometry methods. Nine commercial gelatins of (labeled) bovine, porcine and piscine origin, suspicious (undeclared) commercial injection mixtures of gelatin, and suspicious exudate test materials from two frozen chicken fillets, were collected from suppliers to the food chain across Western Europe. 
In mass spectrometry part, after performing solid phase extraction followed by tryptic digestion, mass spectrometry analysis were applied by using MALDITOF-MS and ESI-LC-MS/MS as in the case of Flaudrops et al. (2015) and Yilmaz et al. (2013), respectively. An inhouse database was formed consisting of 32 species such as bovine, porcine, and piscine, in which; published sequences data, direct sequences data (using LC-ESIMS/MS and Nano LC-MALDI-TOF/TOF), recovery of sequence data from publicly available genomic data and expressed sequence tag libraries data; were collected. The comparison of data was carried out with a program called Biotyper software. A species identification was accepted when a minimum of two species-specific peptides were identified with at least $95 \%$ confidence in the Biotyper result. In cases of single or modified peptide identification manual validation was applied. Among nine of commercial gelatin results, one bovine and one porcine gelatin did not match the labeling origin. Employing mass spectroscopy, the labeled species, in both cases, were found to be major in qualitative amount. By comparing the relative peak intensities of labeled and undeclared gelatin species in this two sample, a lower proportion, ranging between $1 / 10$ and $1 / 17$, was observed. The mass spectrometry method developed in this study was capable of determining the number of hydroxylated proline within peptides, as well, which are indicators of marker peptide degradation. Some peptides were observed to be unchanged in terms of proline hydroxylation and vice versa. For example, among 15 bovine peptides detected, while there is no hydroxylated proline detected for peptide sequence of IGQPGAVGPAGIR with 1192.7 monoisotropic mass; GEPGAVGQPGPPGPSGEEGKR sequence with 2006.9 monoisotropic mass has 3 hydroxylated prolines, Similarly, among 10 porcine peptides detected, GETGPAGPAGPVGPVGAR sequence with monoisotropic mass of 1545.8 has no hydroxylated prolines, whereas GEPGPAGSVGPAGAVGPR sequence with a monoisotropic mass of 1547.8 has one hydroxylated proline (Grundy et al., 2016).

Future quantitative analyses are planned to determine if the additional species were present only at trace levels or significantly higher. This method was more specific and robust than those of some previous methods involving tryptic digestion and MS/MS analysis, in that, it was able to detect some of the published 'bovinedeterminant' peptides when testing porcine gelatin and vice versa (Hidaka and Liu, 2003; Nemati et al., 2004). In phylogenetic trees application Grundy et al. (2016), like as a previous study, find that tracing the occurrence of certain markers and PTMs increased confidence of this method (Buckley et al., 2009).

\section{Discussion}

Among different species of gelatin studied, especially bovine and porcine gelatins are homologous; they have similar structures and physicochemical characteristics; thus, are difficult to differentiate by conventional analytical methods. Commercialized species determination has been limited due to highly denaturing processes used in gelatin manufacturing (Grundy et al., 2016). It can be beneficial to compare the recent analytical methods with regard to their accuracy, sensitivity, price, and applicability/feasibility.

PCR based techniques provide results through DNA sequence level, so it has high specificity, sensitivity, and discriminating power (Nakyinsige et al., 2012). However gelatin is a highly processed meat product and leaves very few amount of DNA after processes and lower chain length fragments due to DNA damage (Fajardo et al., 2010). New PCR techniques such as species specific and real-time PCR may potentially provide reliable and sensitive detection and quantification of different gelatin species. However, there is no study about gelatin differentiating methods conducted with multiplex PCR assays, and real-time PCR can give false negative results (Cai et al., 2012).

An electrophoretic method, SDS-PAGE does not require expensive equipment, high sample purity, and sample preparation. Moreover, the results are not affected by DNA degradation stemmed from gelatin manufacturing process like in PCR (Azira et al., 2014). Nevertheless, it can identify porcine gelatin in bovine gelatin only if the adulteration is at least $5 \%$. That is why it cannot be preferred over PCR in the respect of sensitive differentiation.

FTIR spectroscopy method with ATR can successfully differentiate bovine, porcine, and fish gelatins; however, it requires a threshold concentration of gelatin to be present in a sample that is subjected to analysis. Moreover it is not sufficient to differentiate gelatin species in mixtures (Cebi et al., 2016). Like FTIR, ELISA method requires proper quality and threshold concentration of gelatin species to have sufficient differentiation between bovine, porcine, and fish. It can be preferred over PCR method due to DNA degradation handicap making the determination step troublesome in PCR (Tukiran et al., 2016b).

Conventional chromatography methods such as HPLC alone cannot ensure sufficient differentiation of gelatin species due to hydroxylated proline peptides. That is why they are used in combination with mass spectroscopy or chemometry (Zhang et al., 2006). Methods other than computational ones which involve laboratory practices have to be confirmed and have repeatability under laboratory collaborative studies to assure both accuracy and quality of the results (Azilawati et al., 2015). Certain applications such as using mass spectrometry require high initial costs, more time and skilled stuff. Nevertheless, they provide the most sensitive and accurate results with low concentrations even for gelatin mixtures (Grundy et al., 2016).

A comparison study of a HPLC-MS, ELISA, and PCR technique was published by Grundy et al. (2016), recently. Different concentration (0\% to $4.6 \%)$ of porcine gelatin and chicken exudate simulants were investigated with these three methods. Although developed LCMS/MS method was detected presence of porcine gelatin 
sensitively (1\%), PCR assay was not sufficient to detect porcine gelatin unless it is around $4.6 \%$ level neither do ELISA (Grundy et al., 2016).

Furthermore, in a study, ambient liquid extraction surface analysis mass (LESA-MS) was utilized to differentiate complex mixtures of processed proteins/peptides from bovine, porcine, horse, chicken and turkey meat (Montowska et al., 2015). It is mentioned that they have detected protein-specific heat stable peptide markers in processed food samples. Since thermal processing is one of the handicaps of gelatin differentiation due to destruction of marker peptides and DNA as in the case of chromatographic, spectroscopic, and PCR based methods; it may be beneficial to use this method to determine and differentiate origins of gelatins in thermally processed food.

\section{Conclusion}

More than hundred research articles concerning analytical methods to identify and to differentiate gelatin species of bovine, porcine, and piscine from 2010 up to today have been examined, and 59 of them have been cited as the unique ones among all. Performed analytical methods included combinations of various techniques ranging from chromatography and spectroscopy, to statistical programs and computational databases. Since in almost all studies mentioned here it has been claimed differentiation between gelatins of different origin at certain extend; there arose a matter of sensitivity. The most sensitive results were obtained by two studies, one of which combined HPLC with PCA (a PCA variance of $72 \%$ ), and the other combined Nano LC-MS/MS with a biotyper software $(1 \% \mathrm{w} / \mathrm{w})$. All things considered it can be concluded that a reference limit of detection value for animal origin of gelatin should be assigned by authorities in order to deduce that the differentiation is maintained at high sensitivity.

\section{Funding Statement}

For writing this review, it was not received any specific grant from funding agencies in the public, commercial, or not-for-profit sectors.

\section{References}

Abd Mutalib S, Muin NM, Abdullah A, Hassan O, Mustapha WAW, Sani NA, Maskat MY. 2015. Sensitivity of polymerase chain reaction (PCR)-southern hybridization and conventional PCR analysis for Halal authentication of gelatin capsules. LwtFood Sci Technol 63(1): 714-719. DOI: 10.1016/j.lwt.2015.03.006.

Aida AA, Che Man YB, Raha AR, Son R. 2007. Detection of pig derivatives in food products for halal authentication by polymerase chain reaction-restriction fragment length polymorphism. J. Sci. Food Agric. 87(4): 569-572. DOI: 10.1007/s12161-011-9260-y.

Aina MA, Amin I, Hafidz RNRM, Yaakob CM. 2013. Identification polypeptide biomarkers of porcine skin gelatin by twodimensional electrophoresis. International Food Research Journal. 20(3): 1395-1399. DOI: $10.1080 / 10408398.2016 .1264361$.
Ali ME, Razzak MA, Abd Hamid SB, Rahman MM, Al Amin M, Abd Rashid NR. 2015. Multiplex PCR assay for the detection of five meat species forbidden in Islamic foods. Food Chem. 177: 214-224. DOI: 10.1016/j.foodchem.2014.12.098.

Anonymous. 2016.Gelatin - A Global Strategic Business Report. Available from: http://www.strategyr.com/ Gelatin_Market_Report.asp [13.04.2017]

Azilawati MI, Hashim DM, Jamilah B, Amin I. 2014. Validation of a reverse-phase high-performance liquid chromatography method for the determination of amino acids in gelatins by application of 6-aminoquinolyl-N-hydroxysuccinimidyl carbamate reagent. J Chromatogr A. 1353: 49-56. DOI: 10.1016/j.chroma.2014.04.050.

Azilawati MI, Hashim DM, Jamilah B, Amin I. 2015. RP-HPLC method using 6-aminoquinolyl-N-hydroxysuccinimidyl carbamate incorporated with normalization technique in principal component analysis to differentiate the bovine, porcine and fish gelatins. Food Chem. 172: 368-376. DOI: 10.1016/j.foodchem.2014.09.093.

Azira TN, Man YBC, Hafidz RNRM, Aina MA, Amin I. 2014. Use of principal component analysis for differentiation of gelatine sources based on polypeptide molecular weights. Food Chem. 151: 286-292. DOI: 10.1016/j.foodchem.2013.11.066.

Baziwane D, He Q. 2003. Gelatin: the paramount food additive. Food Rev. Int. 19(4): 423-435. DOI: 10.1081/FRI-120025483.

Benbettaïeb N, Karbowiak T, Brachais CH, Debeaufort F. 2016. Impact of electron beam irradiation on fish gelatin film properties. Food Chem. 195: 11-18. DOI: 10.1016/j.foodchem.2015.03.034. ISSN 0308-8146.

Beranova-Giorgianni S. 2003. Proteome analysis by twodimensional gel electrophoresis and mass spectrometry: strengths and limitations. Trac-Trend Anal Chem. 22(5): 273281. DOI: 10.1016/S0165-9936(03)00508-9.

Boran G, Lawless H., Regenstein J. 2010. Effects of extraction conditions on the sensory and instrumental characteristics of fish gelatin gels. J. Food Sci. 75(9): S469-S476. DOI: 10.1111/j.1750-3841.2010.01827.x.

Buckley M, Collins M, Thomas-Oates J, Wilson JC. 2009. Species identification by analysis of bone collagen using matrix-assisted laser desorption/ionisation time-of-flight mass spectrometry. Rapid Commun. Mass Spectrom. 23(23): 3843-3854. DOI: $10.1002 / \mathrm{rcm} .4316$.

Cai H, Gu XL, Scanlan MS, Ramatlapeng DH, Lively CR. 2012. Real-time PCR assays for detection and quantitation of porcine and bovine DNA in gelatin mixtures and gelatin capsules. J Food Compos Anal. 25(1): 83-87. DOI: 10.1016/j.jfca.2011.06.008.

Cebi N, Durak MZ, Toker OS, Sagdic O, Arici M. 2016. An evaluation of Fourier transforms infrared spectroscopy method for the classification and discrimination of bovine, porcine and fish gelatins. Food Chem. 190: 1109-1115. DOI: 10.1016/j.foodchem.2015.06.065.

Cellulaire B. 2002. Two-dimensional gel electrophoresis in proteomics: old, old fashioned, but it still climbs up the mountains. Proteomics. 2: 3-10. DOI: 10.1002/16159861(200201)2:1<3::AID-PROT3>3.0.CO;2-R.

Chen SY, Liu YP, Yao YG. 2010a. Species authentication of commercial beef jerky based on PCR-RFLP analysis of the mitochondrial 12S rRNA gene. J. Genet. Genomics 37(11): 763-769. DOI: 10.1016/S1673-8527(09)60093-X.

Chen TY, Chen NH, Lin WF, Hwang KL, Huang YC, Hwang DF. 2010 b. Identification of causative fish for a food poisoning in Taiwan by using SDS-PAGE technique. J. Mar. Sci. Technol. 18(4): 593-596. Available from: https://www.researchgate.net/ publication/228661818_Identification_of_Causative_Fish_for_a _Food_Poisioning_in_Taiwan_by_Using_SDSPAGE_Technique[18.05.17].

Cheng XL, Wei F, Xiao XY, Zhao YY, Shi Y, Liu W, Zhang P, Ma SC, Tian SS, Lin RC. 2012. Identification of five gelatins by ultra performance liquid chromatography/time-of-flight mass spectrometry (UPLC/Q-TOF-MS) using principal component analysis. J. Pharm. Biomed. Anal. 62: 191-195. DOI: 10.1016/j.jpba.2011.12.024. 
Cho SM, Gu YS, Kim SB. 2005. Extracting optimization and physical properties of yellowfin tuna (Thunnus albacares) skin gelatin compared to mammalian gelatins. Food Hydrocolloids. 19(2): 221-229. DOI: 10.1016/j.foodhyd.2004.05.005.

Demirhan Y, Ulca P, Senyuva HZ. 2012. Detection of porcine DNA in gelatine and gelatine-containing processed food productsHalal/Kosher authentication. Meat Sci. 90(3): 686-689. DOI: 10.1016/j.meatsci.2011.10.014.

Doi H, Watanabe E, Shibata H, Tanabe S. 2009. A reliable enzyme linked immunosorbent assay for the determination of bovine and porcine gelatin in processed foods. J. Agri. Food Chem. 57(5): 1721-1726. DOI: $10.1021 / \mathrm{jf} 802733 \mathrm{y}$.

Etienne M, Jérôme M, Fleurence J, Rehbein H, Kündiger R, Mendes R, Costa H, Pérez-Martín R, Piñeiro-González C, Craig A. 2000. Identification of fish species after cooking by SDS-PAGE and urea IEF: a collaborative study. J. Agric. Food Chem. 48(7): 2653-2658. Available

from: https://www.researchgate.net/publication/12419846_Identificati on_of_fish_species_after_cooking_by_SDS-

PAGE_and_urea_IEF_a_collaborative_study[18.05.17]

Fajardo V, González I, Rojas M, García T, Martín R. 2010. A review of current PCR-based methodologies for the authentication of meats from game animal species. Trends Food Sci. Technol. 21(8): 408-421. DOI: 10.1016/j.tifs.2010.06.002.

Flaudrops C, Armstrong N, Raoult D, Chabrière E. 2015. Determination of the animal origin of meat and gelatin by MALDI-TOF-MS. J Food Compos Anal. 41: 104-112. DOI: 10.1016/j.jfca.2015.02.009.

GME. 2016. About Gelatin - Raw Material. Available from: http://www.gelatine.org/about-gelatine/manufacturing/rawmaterials.html[13.04.17]

Gómez-Guillén M, Turnay J, Fernández-Diaz M, Ulmo N, Lizarbe M, Montero P. 2002. Structural and physical properties of gelatin extracted from different marine species: a comparative study. Food Hydrocolloids. 16(1): 25-34. DOI: 10.1016/S0268$005 \mathrm{X}(01) 00035-2$.

Griffiths PR, De Haseth JA. 2007. Fourier transform infrared spectrometry. John Wiley \& Sons. ISBN: 0470106298.

Grundy HH, Reece P, Buckley M, Solazzo CM, Dowle AA, Ashford D, Charlton AJ, Wadsley MK, Collins MJ. 2016. A mass spectrometry method for the determination of the species of origin of gelatine in foods and pharmaceutical products. Food Chem. 190: 276-284. DOI: 10.1016/j.foodchem.2015.05.054.

Hanna SE, Connor CJ, Wang HH. 2005. Real-time polymerase chain reaction for the food microbiologist: technologies, applications, and limitations. J. Food Sci. 70(3): R49-R53. DOI: $10.1111 /$ j.1365-2621.2005.tb07149.x.

Hashim D, Man YC, Norakasha R, Shuhaimi M, Salmah Y, Syahariza Z. 2010. Potential use of Fourier transform infrared spectroscopy for differentiation of bovine and porcine gelatins. Food Chem. 118(3): 856-860. DOI: 10.1016/j.foodchem.2009.05.049.

Hidaka S, Liu SY. 2003. Effects of gelatins on calcium phosphate precipitation: a possible application for distinguishing bovine bone gelatin from porcine skin gelatin. J Food Compos Anal. 16(4): 477-483. DOI: 10.1016/s0889-1575(02)00174-6.

Isola D, Marzban G, Selbmann L, Onofri S, Laimer M, Sterflinger K. 2011. Sample preparation and 2-DE procedure for protein expression profiling of black microcolonial fungi. Fungal Biol. 115(10): 971-977. DOI: 10.1016/j.funbio.2011.03.001.

Masuda A, Dohmae N. 2011. Amino acid analysis of sub-picomolar amounts of proteins by precolumn fluorescence derivatization with 6-aminoquinolyl- $N$-hydroxysuccinimidyl carbamate. BioSci. Trends. 5(6): 231-238. DOI: 10.5582/bst.2011.v5.6.231.

Mayer H. 2005. Milk species identification in cheese varieties using electrophoretic, chromatographic and PCR techniques. Int. Dairy J. 15(6): 595-604. DOI: 10.1016/j.idairyj.2004.10.012.

Montowska M, Alexander MR, Tucker GA, Barrett DA. 2015. Authentication of processed meat products by peptidomic analysis using rapid ambient mass spectrometry. Food Chem. 187: 297-304. DOI: 10.1016/j.foodchem.2015.04.078
Murugaiah C, Noor ZM, Mastakim M,Bilung LM, Selamat J, Radu S. 2009. Meat species identification and halal authentication analysis using mitochondrial DNA. Meat Sci. 83: 57-61. DOI: 10.1016/j.meatsci.2009.03.015.

Muyonga J, Cole C, Duodu K. 2004. Fourier transform infrared (FTIR) spectroscopic study of acid soluble collagen and gelatin from skins and bones of young and adult Nile perch (Lates niloticus). Food Chem. 86(3): 325-332. DOI: 10.1016/j.foodchem.2003.09.038.

Nakyinsige K, Man YB, Sazili AQ. 2012. Halal authenticity issues in meat and meat products. Meat Sci. 91 (3): 207-214. DOI: 10.1016/j.meatsci.2012.02.015.

Nemati M, Oveisi MR, Abdollahi H, Sabzevari O. 2004. Differentiation of bovine and porcine gelatins using principal component analysis. J. Pharm. Biomed. Anal. 34(3): 485-492. DOI: $10.1016 / \mathrm{s} 0731-7085(03) 00574-0$.

Nhari RMHR, Ismail A, Man YBC. 2012. Analytical Methods for Gelatin Differentiation from Bovine and Porcine Origins and Food Products. J. Food Sci. 77(1): R42-R46. DOI: 10.1111/j.1750-3841.2011.02514.x.

Nimptsch A, Schibur S, Ihling C, Sinz A, Riemer T, Huster D, Schiller J. 2011. Quantitative analysis of denatured collagen by collagenase digestion and subsequent MALDI-TOF mass spectrometry. Cell Tissue Res. 343(3): 605-617. DOI: 10.1007/s00441-010-1113-2.

Nishihara JC, Champion KM. 2002. Quantitative evaluation of proteins in one-and two-dimensional polyacrylamide gels using a fluorescent stain. Electrophoresis. 23(14): 2203-2215. DOI: 10.1002/1522-2683(200207)23:14<2203::AIDELPS2203>3.0.CO;2-H.

Purvine S, Eppel JT, Yi EC, Goodlett DR. 2003. Shotgun collisioninduced dissociation of peptides using a time of flight mass $\begin{array}{llll}\text { analyzer. } & \text { Proteomics. } 3(6): & 847-850 . & \text { DOI: }\end{array}$ 10.1002/pmic.200300362.

Rezazadeh M, Yamini Y, Seidi S, Aghaei A. 2015. Pulsed electromembrane extraction for analysis of derivatized amino acids: A powerful technique for determination of animal source of gelatin samples. Talanta. 136: 190-197. DOI: 10.1016/j.talanta.2015.01.007.

Rezazadeh M, Yamini Y, Seidi S, Esrafili A. 2012. Pulsed electromembrane extraction: a new concept of electrically enhanced extraction. J Chromatogr A. 1262: 214-218. DOI: 10.1016/j.chroma.2012.08.090.

Saiki RK, Scharf SJ, Faloona F, Mullis KB, Horn GT, Erlich HA, Arnheim N. 1985. Enzymatic amplification of B-globin genomic sequences and restriction site analysis for diagnosis of sickle cell anemia. Science. 230: 4732. DOI: 10.1126/science.2999980.

Schrieber R, Gareis H. 2007. Gelatine handbook: theory and industrial practice. John Wiley \& Sons. ISBN: 3527315489.

Sentandreu MA, Sentandreu E. 2011. Peptide biomarkers as a way to determine meat authenticity. Meat Sci. 89(3):280-285. DOI: 10.1016/j.meatsci.2011.04.028.

Shabani H, Mehdizadeh M, Mousavi SM, Dezfouli EA, Solgi T, Khodaverdi M, Rabiei M, Rastegar H, Alebouyeh M. 2015. Halal authenticity of gelatin using species-specific PCR. Food Chem. 184: 203-206. DOI: 10.1016/j.foodchem.2015.02.140.

Sivakesava S, Irudayaraj J. 2002. Classification of simple and complex sugar adulterants in honey by mid-infrared spectroscopy. Int. J. Food Sci. Technol. 37(4): 351-360. DOI: 10.1046/j.1365-2621.2002.00573.x.

Somma M, Querci M. 2006. The Polymerase Chain Reaction (PCR), in: Querci, M., Jermini, M., den Eede, G.Y. (Eds.), Training Course on The Analysis of Food Samples for the Presence of Genetically Modified Organisms, User Manuel. World Health Organization Regional Office For Europe. pp. 217-218. ISBN: 92-79-02242-3.

Tukiran NA, Ismail A, Mustafa S, Hamid M. 2016a. Determination of porcine gelatin in edible bird's nest by competitive indirect ELISA based on anti-peptide polyclonal antibody. Food Control. 59: 561-566. DOI: 10.1016/j.foodcont.2015.06.039. 
Tukiran NA, Ismail A, Mustafa S, Hamid M. 2016b. Development of antipeptide enzyme-linked immunosorbent assay for determination of gelatin in confectionery products. Int. J. Food Sci. Technol. 51(51): 54-60. DOI: 10.1111/ijfs.12971.

Venien A, Levieux D. 2005. Differentiation of bovine from porcine gelatines using polyclonal anti-peptide antibodies in indirect and competitive indirect ELISA. J. Pharm. Biomed. Anal. 39(34): 418-424. DOI: 10.1016/j.jpba.2005.04.013.

Weber P, Steinhart H, Paschke A. 2009. Competitive Indirect ELISA for the Determination of Parvalbumins from Various Fish Species in Food Grade Fish Gelatins and Isinglass with PARV-19 Anti-parvalbumin Antibodies. J Agr Food Chem. 57(23): 11328-11334. DOI: 10.1021/jf902470e.
Yilmaz MT, Kesmen Z, Baykal B, Sagdic O, Kulen O, Kacar O, Yetim H, Baykal AT. 2013. A novel method to differentiate bovine and porcine gelatins in food products: nanoUPLC-ESIQ-TOF-MS(E) based data independent acquisition technique to detect marker peptides in gelatin. Food Chem. 141(3): 24502458. DOI: 10.1016/j.foodchem.2013.05.096.

Zhang G, Liu T, Wang Q, Chen L, Lei J, Luo J, Ma G, Su Z. 2009. Mass spectrometric detection of marker peptides in tryptic digests of gelatin: A new method to differentiate between bovine and porcine gelatin. Food Hydrocolloids. 23(7): 20012007. DOI: 10.1016/j.foodhyd.2009.03.010.

Zhang G, Sun A, Li W, Liu T, Su Z. 2006. Mass spectrometric analysis of enzymatic digestion of denatured collagen for identification of collagen type. J. Chromatogr. A. 1114(2): 274277. DOI: 10.1016/j.chroma.2006.03.039. 